\title{
EL CRITERIO GEOLÓGICO-GEOMORFOLÓGICO EN LA DETECCIÓN Y MITIGACIÓN DE EVENTOS HIDROLÓGICOS EXTREMOS - SIERRAS DE LA PROVINCIA DE CÓRDOBA
}

\author{
O CRITÉRIO GEOLÓGICO-GEOMORFÓLOGICO NA DESCOBERTA \\ E MITIGAÇÃO DE EVENTOS HIDRÓLOGICOS EXTREMOS - \\ SERRAS DA PROVÍNCIA DE CÓRDOBA
}

\section{THE GEOLOGIC-GEOMORPHOLOGICAL APPROACH IN THE DETECTION AND MITIGATION OF EVENTS HYDROLOGICAL ENDS - SIERRAS DE LA PROVINCIA DE CÓRDOBA}

O. BARBEITO 1

S. AMBROSINO 2

\begin{abstract}
RESUMO
Nos útimos tempos, tendo como causa provável o fenômeno "El Ninõ", ocorreram grandes e repentinas inundações que atingiram pontos turísticos da região serrana da Província de Córdoba, causando muitos danos e mortes. Em todos os casos, a magnitude, dinâmica e alcance dessas inundações pegaram completamante desprevinidos os habitantes da região e os organismos de Defesa Civil, apesar de as características geológicas e geomorfológicas, estudadas em imagens de satélite e de fotografias aéreas antecedentes, indicarem a ocorrência de eventos claramente semelhantes em um passado geológico muito recente, fato também afirmado através de dados históricos. Diante de tais acontecimentos, o INACirsa apontou uma estratégia de mitigação para avaliar as ameaças de inundação, a qual é composta por um sistema telemétrico que, prevendo qualquer perigo, dispara um sinal alertando várias cidades serranas. No caso específico da cidade de Mina Clavero, mediante um acordo firmado com o município, este trabalho, que utiliza como base primordial o critério geológico-morfológico por meio de técnicas de fotointerpretação e teledetecção, além da confirmação e ajuste da informação obtida na base de exames de campo e o resumo e análise de dados históricos, foi selecionado. Como resultado, obteve-se uma carta com previsões de inundações repentinas, indicando sua dinâmica e seu alcance e pondo ênfase especial nas de caráter extremo. Após o término do estudo, as informações cartográficas obtidas foram enviadas ao município. Elas previam a grande enchente do dia 10 de novembro de 1993, espe-
\end{abstract}

INA - Instituto Nacional del Agua y el Ambiente / CIRSA - Centro de Investigaciones de la Region Semiárida / Argentina.

2 INA - Instituto Nacional del Agua y el Ambiente / CIRSA - Centro de Investigaciones de la Region Semiárida / Argentina. 
cificando claramente as suas proporções e julgando a concientização da população, com relação à evacuação, um dos aspectos mais relevantes, o que possibilitou a mitigação pela ação da Defesa Civil. Isso deixa clara a utilidade do emprego do critério geológico-geomorfológico para a detecção e prevenção de fenômenos hidrológicos extremos, muito embora deva-se levar em conta que, nas áreas estudadas, os dados hidrológicos, meteorológicos etc. são temporal e espacialmente insuficientes.

\section{ABSTRACT}

Lately, in the Mountain Region of the County of Cordoba, possibly due to the phenomenon "El Niño", there were extreme sudden floods that affected touristic centers causing important damage and losses of human lives. In all cases, the magnitude and reach of such floods made the residents completely unaware of the organisms in charge of the Civil Defense. Nevertheless the geologic and geomorphologic characteristics analysed in images and satellites and pictures of air antecedents, indicated the occurrence of similar events clearly in a very recent geologic past, which was also corroborated by the historical data. Facing this reality the INA-Cirsa has faced a mitigation strategy that covers the stage of evaluation of the threat supplemented by a telemetric system to alert to several mountain counties. This paper selected as representative, using like primordial base, the geologic-morphologic approach by means of the use of photointerpretation techniques and teledetection and the corroboration and adjustment of the obtained information, based upon field checkups and the summary as well as the analysis of historical data. As a result, a chart of likely threat of sudden floods, the dynamics and reach of flood with special emphasis on those of extreme character was provided. The cartographic information was given previously was to the counties due to growing extreme characteristics similar to what took place on November 10, 1993 whose dynamics and reach were specified clearly in the content of the same one, which made the mitigation easy for the action of the organisms in charge of the Civil Defense helping the population to get autoevacuation. This makes clear that high use of the geologic geomorphologic approaches for the detection and prevention of events with hydrological ends, but keeping in mind that in the studied areas, the hydrologic, meteorological data are understood as the distribution of rain storm.

\section{RESUMEN}

En los últimos tiempos, en la Región serrana de la Provincia de Córdoba, posiblemente con relación al fenómeno el "Niño", tuvieron lugar inundaciones repentinas extremas que afectaron a centros turísticos, ocasionando importantes daños y pérdidas de vidas humanas. En todos los casos, la magnitud, dinámica y alcance de tales inundaciones tomaron totalmente desprevenidos tanto a pobladores, como a los organismos encargados de la Defensa Civil. No obstante, las características geológicas y geomorfológicas, analizadas en imágenes satelitales y fotografías aéreas antecedentes, indicaban claramente la ocurrencia de eventos similares en un pasado geológico muy reciente, hecho además, corroborado por datos históricos. Frente a esta realidad, el INA-Cirsa ha encarado una estrategia de mitigación que cubre la etapa de evaluación de la amenaza complementada con un sistema telemétrico que brinda alerta temprana a diversos municipios serranos. En el caso específico de la Ciudad de Mina Clavero, mediante un convenio firmado con el municipio, se realizó el presente trabajo seleccionado como representativo, utilizando como base primordial, el criterio geológico-geomorfológico mediante el uso de las técnicas de la fotointerpretación y teledetección y la corroboración y ajuste de la información obtenida, sobre la base de chequeos de campo y la recopilación y análisis de datos históricos. Como resultado, se obtuvo una carta de amenaza de inundaciones repentinas indicativa de la dinámica y alcance de las inundaciones, poniendo especial énfasis en las de carácter extremo. La información cartográfica fue entregada al municipio con anterioridad a la creciente extrema que tuvo lugar el 10 de noviembre de 1993, cuya dinámica y alcance se especificaban claramente en el contenido de la misma, lo que posibilitó la mitigación por la acción de los organismos encargados de la Defensa Civil, jugando un papel relevante la concientización de la población (autoevacuación). Esto deja en claro la alta utilidad del empleo del criterio geológico-geomorfológico para la detección y prevención de eventos hidrológicos extremos, pero teniendo en cuenta que en las áreas estudiadas, los datos hidrológicos, meteorológicos etc. son insuficientes tanto en forma espacial como temporal. 


\section{INTRODUCCIÓN}

Las Sierras de la Provincia de Córdoba (figura 1) se localizan entre los $30^{\circ}$ y $34^{\circ}$ de latitud sur y los $63^{\circ}$ y $65^{\circ}$ de longitud oeste, constituidas por tres lineamientos norte-sur de bloques elevados por efecto de fallas regionales: el Cordón Oriental, el Cordón Central y el Cordón Occidental.
Figura 1

En el Cordón Central, con altitudes por sobre de los 2.000 m.s.n.m (Sierras de Comechingones, Cumbres de Achala y Sierras Grandes), tienen nacientes los principales sistemas hidrológicos de la Provincia, según cuencas de recepción de carácter torrencial del orden de los 300 a $500 \mathrm{~km}^{2}$.

El medio receptor de essas cuencas se caracteriza por la predominancia de relieve fuerte con accidentes frecuentemente asociados a la tectónica (escarpes, cornisas, quebradas, etc.) y la marcada predominancia de un basamento cristalino antiguo (metamórficoplutónico), que soporta coberturas residuales someras o discontinuas que alternan con elevados porcentajes de roca desnuda. La vegetación natural es en los niveles inferiores, de tipo arbustivo de textura abierta, y en los niveles medios y superiores, de tipo alpino, representada por pastizales de altura de densidad variable y bosquecillos de altura densos, limitados a las quebradas en donde se dan condiciones de microclima favorables (Barbeito, Herrero \& Ambrosino1983)

Por su parte, las condiciones climáticas se ajustan a parámetros de semiaridez, con precipitaciones medias del orden de los $850 \mathrm{~mm}$ anuales y concentración de lluvias en el periodo octubre-marzo.

El uso actual, dado la baja aptitud de los suelos, se limita a la actividad forestal poco intensa (coníferas) y a la ganadería extensiva en gran parte limitada por la topografía accidentada.

La energía del relieve, conjuntamente con la baja permeabilidad de los materiales geológicos de superficie y la insuficiente protección hidrológica que ofrece la vegetación por condicionamiento natural, a la vez disminuida por la alteración por efecto de incendios periódicos, sumado a la ocurrencia de tormentas convectivas severas por acción del efecto orográfico, predisponen al ambiente a una alta tendencia a la generación de crecientes repentinas de magnitud (Barbeito, Herrero \& Ambrosino1983).

Figura 2

La Ciudad de Mina Clavero (figura 2), que constituye uno de los centros turísticos mas importantes de la Provincia, se localiza al pié de la vertiente occidental abrupta del Cordón Central (Cumbres de Achala), a las márgenes del colector principal de la cuenca de recepción, inmediatamente a la salida del bloque montañoso. Las particularidades naturales liga- 
BARBEITO, O.;AMBROSINO, S. El criterio geológico-geomorfológico en la detección y...

das a la generación de las crecientes repentinas descriptas adquieren, aquí, la mayor significación, hecho que se corrobora con los antecedentes históricos (Barbeito \& Ambrosino 1993).

Frente a esta realidad, es que se encara el presente trabajo, partiendo de la premisa fundamental de que en el manejo de las amenazas naturales las medidas previas a la ocurrencia de los desastres, entre las que se incluyen la mitigación, son las más efectivas en términos de costo y tiempo de aplicación para reducir el número de fatalidades y la destrucción de propiedades (OEA - DDRMA 1991).

\section{OBJETIVOS}

Los objetivos del presente trabajo, dentro del marco de las estrategias para el manejo de las amenazas naturales, estan orientados a detectar y evaluar las áreas bajo amenaza de crecientes repentinas, en particular de carácter extremo, mediante estudios geológicos y geomorfológicos aplicados, utilizando las técnicas de la teledetección y fotointerpretación.

\section{MATERIALES Y METODOS}

La información temática se obtuvo del análisis de imágenes satelitales (cuartos de imagen) a escala 1: 250.000 en banda 7 del año 1983.TM. a escala 1: 100.000 y fotografías aéreas a escala aproximada 1: 20.000 y a escala 1: 5.000 del año 1970 y como base topográfica se utilizaron las Hojas Mina Clavero y

Cuadro 1: Formas planas y verticales.
Panaholma a escala 1: 50.000 editadas por el Instituto Geográfico Militar (IGM).

La metodología empleada consta de dos niveles interactivos: un primer nivel regional y un segundo nivel de semidetalle y detalle. En este nivel, mediante el análisis de las imágenes satelitales, se realizó a nivel de cuenca hidrográfica el reconocimiento, definición, caracterización y mapeo de los siguientes aspectos:

- Clases litológicas dominantes de acuerdo fundamentalmente a los parámetros ligados a la permeabilidad (génesis, estructura, grado de rocosidad, texturas etc.);

- Sistema de drenaje a nivel de cuenca y subcuencas;

- Pendientes naturales en base a su inclinación y distribución;

- Vegetación natural según fisonomía y densidad de cobertura (enfoque fisonómico-estructural). Uso actual.

Seguidamente, los datos temáticos fueron volcados a mapas a escala 1: 100.000. De la intersección de los mapas de materiales geológicos de superficie y las pendientes naturales, se obtuvo un mapa de clases geomorfológicas definidas en base a la naturaleza del terreno, la permeabilidad e inclinación, información esta que cotejada con el cálculo y análisis de las formas planas y verticales de la cuenca (áreas, perímetros, formas, pendiente medias, etc.) (ver cuadro 1), posibilitaron el conocimiento del grado a la tendencia a la generación de crecientes repentinas que presenta la cuenca.
Por su parte, en el segundo nivel mediante análisis de fotointeropretación a nivel de semidetalle y detalle empleando las fotografías aéreas a escala 1: 20.000 y 1 : 5.000 , estuvo centrado en el reconocimiento, definición y caracterización de los siguientes aspectos:

- Formaciones geológicas;

- Ambientes y unidades hidrogeogeomor- fológicas, con especial énfasis en las trazas y elementos indicativos de la dinámica de las inundaciones;

- Situaciones de inestabilidad actuales y potenciales ligadas a la tendencia evolutiva de la erosión de márgenes (estrangulamientos de meandros, desbordes en paleocauces, etc.). 
BARBEITO, O.; AMBROSINO, S. El criterio geológico-geomorfológico en la detección y...

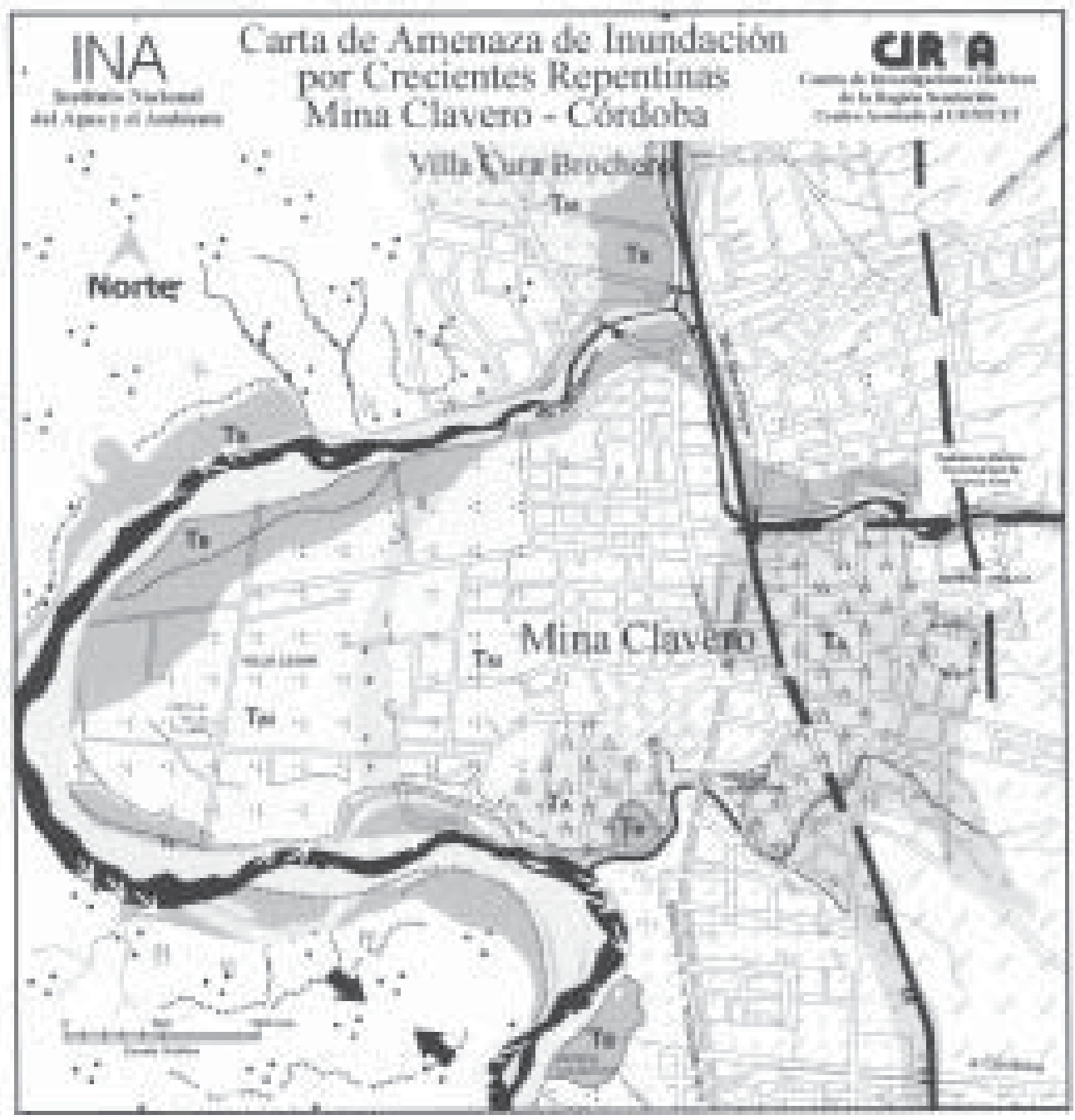

Mapa 1: mapa de risco de inundação. Mina Clavero - Córdoba. 
BARBEITO, O.;AMBROSINO, S. El criterio geológico-geomorfológico en la detección y...

La información obtenida chequeada en campaña, mediante un exhaustivo control in-situ y ajustada en base a la obtención y análisis de la información histórica recabada de antiguos pobladores de la zona (información de alta utilidad por su veracidad y exactitud), posibilitó obtener la zonificación final, considerando las áreas inundables ante las ocurrencias de eventos ordinarios y extremos. La cartografía final, se obtuvo en colores a escala catastral (1: 5.000).

\section{RESULTADOS}

CARACTERÍSTICAS DE LA CUENCA HÍDRICA Y TENDENCIA A LA GENERACIÓN DE CRECIEN-TES REPENTINAS

La Ciudad de Mina Clavero se comprende en la cuenca del río de Los Sauces de carácter endorreico y régimen de escurrimiento pluvial permanente hasta el embalse de La Viña, a partir de donde luego de un breve recorrido se insume en los materiales permeables (fluviotorrenciales) que rellenan los bolsones occidentales de la Provincia de Córdoba (Olsacher 1972).

Las subcuencas de los ríos Mina Clavero y Panaholma, que la componen, conforman el área de recepción del sistema. La primera se conforma por los ríos Del Sauce, Las Manzanas y Hondo, abarcando el conjunto una superficie de $175 \mathrm{~km}^{2}$ hasta el centro de la ciudad homónima. El cauce principal desde las nacientes (2.262 m.s.n.m) hasta el centro de la población (880 m.s.n.m), tiene una longitud de $17 \mathrm{Km}$, lo que resuelve una pendiente media de $5,41 \%$. Por su parte, la segunda, la conforman los ríos Los Hornillos, Laguna Verde y San Lorenzo, abarcando el conjunto una superficie de $425 \mathrm{~km}^{2}$. El cauce principal (Laguna Verde) tiene nacientes a una altitud de 2.270 m.s.n.m. y un recorrido de $57 \mathrm{~km}$ hasta la confluencia con el río Mina Clavero (pendiente media 2,36 \%) (Barbeito \& Ambrosino 1993).

De la confluencia de ambas subcuencas, se genera el río de los Sauces que surca la depresión del valle de San Alberto, flanqueada al este por los bloques de las Cumbres de Achala y al oeste por los de las Sierra de Pocho (ver mapa 1).

El paisaje geomorfológico, donde tienen desarrollo las áreas de recepción, corresponde a la vertiente occidental de las Cumbres de Achala (Cordón Central, ver mapa 2), genéticamente relacionado a rechazos o abruptos de falla compuestos, según bloques descendientes en gradería por efecto de un sistema principal de fallas morfogenéticas N-S, particularidad que resuelve un relieve enérgico manifiesto en frecuentes cornisas, quebradas profundas y laderas de fuerte inclinación.

Los procesos evolutivos del paisaje, dadas las condiciones litológicas y climáticas, se limitan a la disgregación mecánica moderada (arenización) por efecto de la crioclastía, fruto de la variación térmica diur-

Cuadro 2: para mayores referencias ver texto en punto 4.1

\begin{tabular}{|c|c|c|c|c|c|c|c|c|}
\hline & ITC & LOGÍA & \begin{tabular}{|l} 
ELIEVE \\
ROCOSIDAD
\end{tabular} & $\begin{array}{c}\text { P1 } \\
\text { PLANO } \\
(0-3 \%)\end{array}$ & $\begin{array}{c}\text { P2 } \\
\text { SUAVE } \\
(3-7 \%)\end{array}$ & $\begin{array}{c}\text { P3 } \\
\text { MEDIANO } \\
(7-12 \%)\end{array}$ & $\begin{array}{c}\text { P4 } \\
\text { ACCIDENT. } \\
\text { FUERTE } \\
(12-35 \%)\end{array}$ & $\begin{array}{c}\text { P1 } \\
\text { MUY FUER. } \\
\text { ESCARPADO } \\
(+35 \%)\end{array}$ \\
\hline$\stackrel{\infty}{\Sigma}$ & & MASIVAS & $\begin{array}{c}\mathrm{R} \\
\begin{array}{c}\text { ROCOSIDAD } \\
(+50 \%)\end{array}\end{array}$ & & & & $A_{R}$ & \\
\hline$\frac{\bar{s}}{\frac{\mathscr{S}}{\alpha}}$ & 1 & Granitos & $\begin{array}{c}\text { S } \\
\text { ROCOSIDAD } \\
(-50 \%)\end{array}$ & & & & A & s \\
\hline 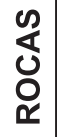 & 2 & $\begin{array}{c}\text { DE ESQUISTODIAD } \\
\text { POCO DEFINIDA } \\
\text { Gneiss }\end{array}$ & & & & & B2 & \\
\hline 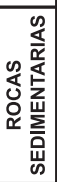 & 3 & $\begin{array}{l}\text { CLASTICAS NO } \\
\text { CONSOLIDADAS } \\
\text { Gravas, Arenas, } \\
\text { Dep. Limoloéssicos }\end{array}$ & & E1 & E2 & E3 & & \\
\hline
\end{tabular}


BARBEITO, O.;AMBROSINO, S. El criterio geológico-geomorfológico en la detección y...

Mapa 2: mapa de classes geomorfológicas esquemático de la Cuenca de Río Clavero - Provincia de Córdoba.

na debido a la altitud, y a procesos de gravedad, según caídas libres de bloques que se circunscriben a las quebradas.

El material geológico está representado por una intrusión ígnea regional (batolito de Achala), en el que predomina netamente la roca granítica con intrusiones de carácter pegmatítico y aplítico (Olsacher 1972), (Gordillo \& Lencinas 1979) sobre la que evolucionaron coberturas residuales muy someras y discontinuas que alternan con porcentajes de roca desnuda superiores al 50\% (Barbeito, Herrero \& Ambrosino 1981).

La vegetación, supeditada a la presencia de coberturas residuales, es de pastizales de altura discontinuos en los niveles superiores, de arbustal abierto con sustrato de pastizales discontinuos en los medios, que se extienden alternando con monte serrano de 
densidad media distribuido en forma puntual a quebradas con condiciones de microclima.

La energía del relieve y el tipo litológico dominante (granito) resuelven la neta predominancia de las clases geomorfológicas Ar y As (ver cuadro 2), pero extendida la primera definida por la mínima permeabilidad y máxima inclinación de los terrenos.

Esto, conjuntamente con las formas planas y verticales del sistema de drenaje (ver cuadro 1), el bajo grado de protección hidrológica que brinda la vegetación natural, a lo que se le suma la ocurrencia de tormentas convectivas por el efecto orográfico, determina una alta tendencia a la generación de crecientes repentinas de magnitud, que se destaca en el caso de la subcuenca del río Mina Clavero.

CONDICIONES GEOLÓGICAS Y GEOMORFOLÓGICAS DE LA CIUDAD Y SU ENTORNO Y RELACIÓN CON EL GRADO DE AMENAZA

La ciudad de Mina Clavero y su entorno se extiende, en su mayor parte, sobre la baja pendiente de la escarpa tectónica de los bloques que integran las Cumbres de Achala, a ambas márgenes del canal de descarga de la cuenca de recepción del río homónimo inmediatamente a la salida de la sierra, y, en parte, sobre el borde oriental de la depresión del valle de San Alberto, en donde el río Mina Clavero confluye con el río Panholma.

En el primer caso, la litología y la estructura geológica juegan un papel preponderante en el grado de amenaza. El río atraviesa la zona urbana encajado en el basamento cristalino (granito) por efecto de una falla longitudinal en primera instancia OE y luego N-S en cuyo trazo confluye frontalmente con el río Panaholma, también controlado por dicha falla (ver mapa 2). Aquí, el río, debido a la marcada predominancia del arranque y transporte en respuesta a la fuerte energía del relieve y la estabilidad de márgenes dada por el tipo litológico, no ha generado un típico lecho de inundación. Como tal, actúa sobre la margen derecha un nivel de terraza de erosión labrada en el basamento con una débil cobertura de material fluvial, sobre la que se asienta estructura edilicia. La dinámica de las crecidas se caracteriza por el control que producen las fallas en el desarrollo lateral y en el incremento vertical y avance frontal con fuerte poder destructivo de estas y el significativo grado de amenaza que involucran.

A diferencia en el paisaje del Valle de San Alberto, la situación geomorfológica e hidrológica es diferente. Aquí, a partir de la confluencia del río Mina Clavero con el río Panaholma, se genera el río De los Sauces a cuyas márgenes se sitúan obras edilicias aisladas y sectores de campamentismo. El canal colector de la cuenca de recepción del río Panaholma tiene un recorrido de 19 $\mathrm{km}$ en el ámbito del valle, hasta la confluencia, hecho que involucra un retardo temporal del pico de crecida con respecto a la subcuenca del río Mina Clavero, que solo recorre $3,5 \mathrm{~km}$, lo que da lugar a la generación de dos picos de crecida y al incremento del caudal.

Inmediatamente aguas abajo de la confluencia, el colector pierde en gran parte el control estructural y comienza a adoptar un patrón de escurrimiento meandriforme debido a un incremento en la carga sedimentaria, producto del brusco cambio de pendiente entre la vertiente de la sierra y el valle. En primera instancia comprendido dentro del ejido urbano, el río describe un amplio meandro labrado en los rellenos aluvionales en donde la dinámica se caracteriza por la tendencia de la erosión de márgenes ligada a la evolución del meandro favorecida por el carácter friable de las márgenes. Al comienzo del meandro, el río corre encajado sobre rocas graníticas del basamento cristalino lo que imposibilita la tendencia al estrangulamiento en ese sector, pero aguas abajo luego de describir la amplia curva, siguiendo la dinámica características de estas geoformas con erosión en la parte externa, deposición en la interna y migración aguas abajo, se evidencia una situación potencial cierta de estrangulamiento (ver mapa 2).

En este tramo del río, a diferencia del tramo urbano antecedente, el río ha generado un lecho de inundación periódico y un lecho de inundación episódico actuando en parte como tal, un nivel de terraza (poligenética) bajo inundable, unidades que se distinguen claramente en el análisis fotogeomor-fológico. Es en este tramo, en donde debe ponerse mayor atención en la adopción de medidas de mitigación no-estructurales y estructurales, pero teniendo en cuenta que la tendencia del crecimiento urbano es en ese sentido.

\section{ZONIFICACIÓN Y ELABORACIÓN DE LACARTADE AMENAZA POR INUNDACIONES}

El análisis de los datos fotogeológicos y fotogeomorfológicos a nivel de detalle en las áreas urbanas y periurbanas, conjuntamente con la recopilación, selección y análisis de datos históricos y brindados por antiguos pobladores, posibilitó zonificar las áreas bajo amenaza, en base a la dinámica de las inundaciones y a su recurrencia, de acuerdo a la siguiente clasificación (ONU 1976, modificada):

Zonas sin amenaza de inundación: comprenden aquellos terrenos que no están afectados por acción del río y solo lo están por cuencas laterales poco significativas, que no entrañan riesgo para bienes y personas. 
BARBEITO, O.;AMBROSINO, S. El criterio geológico-geomorfológico en la detección y...

Usos y restricciones: no existen restricciones y solo para los planes de uso, deben considerarse características geotécnicas, relieve, escurrimiento pluvial, etc.

Zonas con amenaza de inundación: comprenden los terrenos que en mayor o menor medida están afectados por acción del río y que en base a la posición geomorfológica que ocupen y la actividad hídrica se distinguen:

Zonas de alta amenaza

Desde el punto de vista geológico y geomor-fológico y la recurrencia con que se producen las crecientes, se distinguen dos subzonas:

Sub-Zona (a) - Comprende el ámbito del Lecho Ordinario (zona prohibida) claramente evidenciado tanto del punto de vista geológico (arenas, gravas, rodados, etc.) como geomorfológico (riberas claras); constituyen las zonas más críticas, en donde las crecientes repentinas tienen recurrencia anual. Usos y restricciones: solo aptas para balnearios, solarium y recreación.

Sub-Zona (b) - Comprende los terrenos incluidos dentro del ámbito del lecho de inundación periódico que se activa con recurrencias entre 5 y 10 años cuando los caudales superan la capacidad de transporte del lecho ordinario. Usos y restricciones: en base a la marcada actividad hídrica del ambiente, no es recomendable la residencia permanente de personas ni la instalación de obras de infraestructura en general, sin la debida planificación (puentes, líneas eléctricas, tuberías de gas, etc.) y solo son recomendables para recreación, campos de deporte, etc.

En el ámbito del lecho de inundación episódico, cuya actividad está ligada a la ocurrencia de crecientes de alta recurrencia y carácter extraordinario, el aspecto hidrodinámico regido por las condiciones geomor-fológicas permite diferenciar dos zonas en base al poder destructivo de las aguas de crecida y la amenaza que implican:

\section{Zona restringida}

La dinámica fluvial se caracteriza por el avance frontal de la crecida con fuerte poder destructivo. La omisión de esta situación por parte del hombre debido a la alta recurrencia con que estos sectores se activan potencia la amenaza y el riesgo.

\section{Zona de baja amenaza}

Se incluyen los sectores en donde la dinámica fluvial se caracteriza por la expansión lateral de las aguas de crecida (curvas internas) con predominancia de situaciones de anegamiento con bajo poder destructivo de las crecientes. Usos y restricciones: es en estas zonas del ámbito fluvial en donde las medidas previas al evento, entre las que se destaca la evaluación de la amenaza, adquieren mayor significación. La zonificación y concientización de la población juegan un papel fundamental en la mitigación, al posibilitar la autoevacuación.

DINÁMICA DE LA INUNDACIÓN DE NOVIEMBRE DE 1993 Y SU CORRESPONDENCIA CON LA CARTA DE AMENAZA PRELIMINAR (BARBEITO \& AMBROSINO 1993)

En la noche del 10 de Noviembre y la madrugada del 11 de Noviembre de 1993, una tormenta de carácter convectivo afectó con mayor magnitud e intensidad la vertiente occidental de las Cumbres de Achala, en la zona que tienen sus nacientes los ríos Nono y Mina Clavero. El milimetraje ponderado en la alta cuenca, en base a registros de las zonas aledañas, fue de 165 milímetros en tres horas, lo que certifica la ocurrencia de un fenómeno de magnitud. El pico de la creciente ingresó con un caudal estimado de $2.200 \mathrm{~m}^{3} / \mathrm{seg}$.

De una evaluación realizada en campaña con posterioridad al evento, quedó en evidencia la activación total del lecho de inundación periódico y del lecho de inundación episódico del río Mina Clavero hasta la confluencia con el río Panaholma, y totalmente el lecho periódico y parcialmente el episódico, aguas abajo de dicha confluencia en el río de Los Sauces, unidades estas definidas y mapeadas claramente como zonas de amenaza en el estudio preliminar. Aguas abajo de dicha confluencia, estas unidades si bien se activaron, no alcanzaron los límites definidos, lo cual con seguridad está indicando que, en el río Panaholma, el fenómeno meteorológico no alcanzó la misma magnitud que en la cuenca del río Mina Clavero.

Es importante destacar, en base al análisis de las características de la cuenca, que el estado de alteración de la misma tuvo escasa participación en la magnitud que alcanzó la creciente, dado que mas del $90 \%$ de su superficie corresponde a terrenos de muy baja aptitud (clase VIII), hecho que restringe en gran medida su uso. Esto, a la vez se refuerza mediante las evidencias fotogeológicas y fotogeomorfológicas, que indican la ocurrencia de una creciente de características similares en el pasado geológico reciente, cuando la cuenca se encontraba en estado natural. Iguales conclusiones pueden sacarse en el caso de la creciente histórica que afectó a la localidad de San Carlos Minas (1992).

\section{ALCANCEY DISCUSIÓN DE LOS RESULTADOS}

Es importante señalar que la definición de áreas de inundación, en base a el empleo de las técnicas de la teledetección y fotointerpretación, no puede relacionarse por sí misma directamente con las probabilidades de 
repetición, lo cual debe evaluarse mediante estudios hidrológicos específicos. No obstante, en zonas en donde no es suficiente la información de base en ese sentido, como así también, de índole meteorológica, las áreas de inundación delineadas mediante la aplicación de estas técnicas y mediante el empleo del criterio GEOLÓGICO-GEOMORFOLÓGICO, conjuntamente con datos históricos sobre inundaciones, permiten relacionar las posibilidades de ocurrencia de un evento en corto plazo, bajo costo y suficiente precisión.

El uso de fotogramas aéreos permite la visión estereoscópica, posibilitando definir con claridad y aceptable precisión los distintos componentes de los ámbitos fluviales, como así también, la dinámica de las aguas en períodos de crecientes mediante el análisis de patrones y trazas característicos, tanto de carácter periódico como episódico, como así también las situaciones actuales de amenaza que puedan derivar de la tendencia de la erosión de márgenes (estrangula-mientos, cambios de curso, etc.).

La aplicación de esta técnica, suministra información que involucra la seguridad de propiedades, vidas de vecinos y turistas y brinda información de partida para las restricciones básicas de uso y para la acción de los organismos encargados de la defensa civil, cubriendo la etapa de concientización de la población. Además, el empleo de esta tecnología a mas de cubrir la etapa de evaluación de la amenaza, constituye una base de información de alta utilidad para los planes de ordenación de cuencas hídricas, por cuanto brinda conocimiento integral referente a la naturaleza del terreno y los procesos dinámicos que en el actúan.

\section{CONCLUSIONES Y RECOMENDACIONES}

- De las cuencas de recepción del río de Los Sauces, la subcuenca del río Mina Clavero es la que presenta mayor tendencia a la generación de crecientes repentinas de magnitud con considerables picos de crecida. Entre los factores con mayor incidencia en tal tendencia se destacan: la fuerte energía del relieve condicionada por el aspecto tectónico, la baja permeabilidad del sustrato rocoso de carácter cristalino, las formas planas y verticales del sistema de drenaje y la ocurrencia de tormentas convectivas severas por el efecto orográfico.

- El grado de amenaza por crecientes repentinas a que está expuesta la Ciudad de Mina Clavero está en gran parte supeditado a la constitución geológica y geomorfológica de la cuenca hídrica y el grado de amenaza-riesgo, enteramente a la posición geomorfológica que ocupa la Ciudad y su entorno a las márgenes del canal colector, inmediatamente a la salida de la cuenca de recepción y la distribución de las áreas urbanizadas, con respecto a los ambientes, unidades y elementos hidrogeomor-fológicos que lo componen.

- El tramo sobre el río Mina Clavero antes de su confluencia con el río Panaholma, es en respuesta al corto tiempo de llegada del pico de crecida (aproximadamente 1 hora), la dinámica fluvial que implica el acrecimiento vertical de las crecidas de rápida traslación y fuerte poder destructivo y el grado de ocupación del sector, es el que presenta la situación de riesgo mas significativa, en particular ante la ocurrencia de eventos extremos.

- Aguas abajo de la confluencia con el río Panaholma, el grado de amenaza-riesgo decrece en función al cambio de la dinámica fluvial y el menor grado ocupacional. No obstante, la amenaza por erosión de márgenes asociada a la tendencia evolutiva del meandro, constituye una situación de inestabilidad que debe ser considerada convenientemente para mitigar las situaciones potenciales de riesgo. Para tal fin, deben implementarse medidas estructurales y no-estructurales a corto plazo.

- Los datos cartográficos obtenidos complementados con los aportados por la red telemétrica instalada en la cuenca (lluvia-altura de ríos) permitieron implementar una estrategia de mitigación dirigida en particular brindar la alerta temprana ante la ocurrencia de eventos extraordinarios como los que tuvieron lugar en los últimos años en la Provincia.

- La información lograda mediante planes de divulgación específicos y en general a nivel de organismos públicos y privados, posibilitaron la implementación de las estrategias de la Defensa Civil (ubicación y reubicación de centros estratégicos, planes de evacuación, asistencia, etc.) y la concientización de la población, dirigida a lograr la autoevacuación.

- Los datos meteorológicos, hidrológicos y geomorfológicos, certifican el carácter extraordinario del evento atmosférico del $10 \mathrm{de}$ Noviembre de 1993, que generó la creciente episódica que afectó a la población de Mina Clavero; y la predicción de sus efectos quedó claramente manifiesta en la cartografía preliminar que define las zonas de riesgo, oportunamente entregada a las autoridades. 


\section{REFERENCIAS}

Ayala C.G. 1988. Introducción a los Riesgos Geológicos. In: Riesgos Geológicos. Madrid, Instituto Geológico y Minero de España, 3-19.

Barbeito O. \& Ambrosino S. 1993. Geomorphological study of San Carlos Minas Catastrophe, Córdoba Province, Argentine. In: Simpósio de Recursos Hídricos do Cone Sul, 1, Gramados, Anales.

Barbeito O., Herrero M. \& Ambrosino S. 1981. Materiales geológicos de superficie y suelos residuales y su incidencia en la erosión. Sierras Pampeanas de Córdoba. Pub. Inéd. CIRSA. Cba.

Coque R. 1983. Geomorfología. Editorial Omega.

Desastres, planificación y desarrollo. Manejo de amenazas naturales para reducir los daños. OEA/DDRMA. 1991. p. 80.

Gordillo C.E. \& Lencinas A.N. 1979. Sierras Pampeanas de Córdoba y San Luis. In: Simposio de Geología, 2,
Rep. Arg., Acad. Nac. de Ciencias de Córdoba, Anales.

Hermelin M., Mejía O. \& Velásquez. 1990. Some reflexions about the San Carlos catastrophe. S. Agid report. Environmental Geology and applied geomorphology in Colombia, 16: 115-128.

Organización de las Naciones Unidas. ONU. 1976. Prevención y mitigación de los desastres naturales. Compendio de los Conocimientos Actuales. Volumen II.

Olsacher J. 1972. Descripción de la Hoja 21h, Cerro Champaquí. Servicio Nacional Geológico Minero. 1 mapa, escala 1: 200.000. Boletín 133.

Sayago J.M. 1978. Geomorfología del valle de San Alberto. Provincia de Córdoba. In: Congreso Geológico Argentino, 7, Neuquén, Actas, 2: 80-107.

Sayago J. M. 1980. Geomorfología aplicada a hidrología y suelos en el valle de San Alberto. Provincia de Córdoba. Acta geológica Lilloana, Tomo 15: 2. 